\title{
Correlation between functional disorders of the masticatory system and speech sound disorders in children aged $7-10$ years
}

\section{Zależność pomiędzy zaburzeniami czynnościowymi narządu żucia a nieprawidłowościami wymowy u dzieci w wieku od 7 do 10 lat}

\author{
Justyna Grudziąż-Sękowska ${ }^{1, A-F}$, Dorota Olczak-Kowalczyk ${ }^{2, A, C, D, F}$, , Małgorzata Zadurska ${ }^{3, A, C, E, F}$ \\ ${ }^{1}$ Center of Postgraduate Medical Education, Public Health School, Warszawa, Poland \\ ${ }^{2}$ Department of Pediatric Dentistry, Faculty of Medicine and Dentistry, Warsaw Medical University, Poland \\ ${ }^{3}$ Department of Orthodontics, Faculty of Medicine and Dentistry, Warsaw Medical University, Poland \\ A - research concept and design; B - collection and/or assembly of data; C - data analysis and interpretation; \\ $D$ - writing the article; $E$ - critical revision of the article; $F$ - final approval of the article
}

Address for correspondence

Justyna Grudziąż-Sękowska

E-mail:jgrudziaz@cmkp.edu.pl

Funding sources

None declared

Conflict of interest

None declared

Received on 0ctober 7, 2017

Reviewed on January 30, 2018

Accepted on March 1, 2018

DOI

$10.17219 / \mathrm{dmp} / 86006$

Copyright

(c) 2018 by Wroclaw Medical University

and Polish Dental Society

This is an article distributed under the terms of the

Creative Commons Attribution Non-Commercial License

(http://creativecommons.org/licenses/by-nc-nd/4.0/)

\begin{abstract}
Background. Masticatory system and speech sound disorders concur, have the same causes and similar consequences - both increase the risk of dental and periodontal diseases.

Objectives. The study was conducted to establish the correlation between functional disorders of the masticatory system and speech sound disorders.

Material and methods. Three hundred patients aged 7-10 years were examined to detect functional disorders of the masticatory system and speech sound disorders. Functional disorders were assessed in patients with and without speech sound disorders.

Results. According to the study results, functional disorders of the masticatory system concur more often with speech sound disorders than with correct articulation and lead to speech sound disorders. There is a strong correlation between:

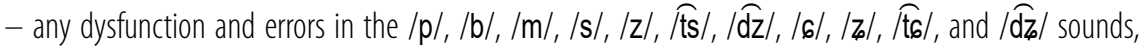

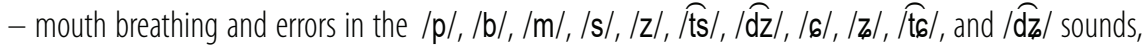

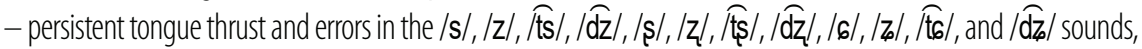
and

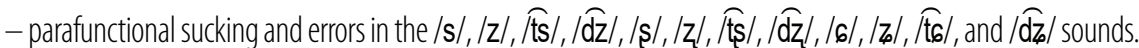

Conclusions. To implement effective and early prevention and treatment, it is crucial to know the correlation between the masticatory system and speech sound disorders, as it reduces treatment duration and minimizes relapses of not only communication disorders, but also of concurrent masticatory system disorders.

Key words: prevention, malocclusion, speech sound disorders, dental care in children

Słowa kluczowe: profilaktyka, wada zgryzu, wady wymowy, opieka stomatologiczna dzieci 
Early orthodontic intervention and logopedic follow-up include all preventive, diagnostic, therapeutic, tutorial, and promoting steps aimed at preventing, limiting or eliminating speech sound and communication disorders, and attenuating their consequences. Orthodontic and logopedic prevention also includes the assessment of biological characteristics, defined as morphology and functioning appropriate for a given age.

Masticatory system and speech sound disorders concur, have common causes and similar consequences for the teeth, increasing the risk of dental and periodontal diseases. Both are featured together in many dental, orthodontic, laryngological, phoniatric, and logopedic studies. These studies cover various functional disorders, such as improper swallowing or oral breathing, and speech sound disorders. ${ }^{1}$ However, there have been no studies simultaneously featuring the many parafunctional habits and dysfunctions of the masticatory system, in the broad meaning of the terms, and correlating them to respective speech sound disorders. ${ }^{2,3}$ With such studies, dentists would be able to take part in the debate on the risk factors of speech sound disorders and on the impact of the latter on the oral cavity.

The aim of the present study was to define the correlations between functional disorders of the masticatory system and respective speech sound disorders in children aged $7-10$ years.

\section{Material and methods}

Children aged 7-10 years attending primary schools in Warszawa, Poland, were qualified for the study. The inclusion criteria were as follows: children born between 2001 and 2004, with a written consent of their legal guardian to participate in the study. The exclusion criteria, aimed to increase the statistical significance of the results, included: cleft lip or palate, congenital anomalies with dysmorphic features within the facial bones of the skull, neurological disorders, mental diseases, intellectual disability, psychomotor retardation, delayed speech development, and hearing loss. Parents or legal guardians were informed verbally and in writing about the objective and scope of the study, techniques employed and data use, and were asked to sign a consent form regarding their child's participation. Children's caregivers were also given a medical interview questionnaire on dysfunctions and parafunctional habits. Dental and logopedic examination was performed between 2010 and 2012 by 1 dentist who was also a speech therapist. Examination was conducted at the school premises.

Dental and logopedic examination assessed the dysfunctions of the masticatory system, occlusal and nonocclusal parafunctional habits, dental and medical treat- ments underway, and potential logopedic treatment. Masticatory system examination encompassed:

- functional status of the masticatory system,

- dysfunctions such as oral breathing, persistent tongue thrust and lazy chewing,

- occlusal parafunctional habits (teeth grinding and clenching), and

- non-occlusal parafunctional habits (prolonged pacifier use, prolonged bottle feeding, sucking habits, nail biting, and lip or mucosa biting).

Logopedic examination assessed the articulation of Polish phonemes in 3 positions: initial, medial and final. All Polish phonemes were expressed according to the International Phonetic Alphabet.

Three hundred children participated in the study. Two groups were created after the logopedic examination:

1. treatment group - with speech sound disorders (161 patients, mean age \pm 8.26 years), and

2. control group - without speech sound disorders (139 patients, mean age \pm 8.89 years).

Statistical analysis was performed using SPSS v. 14.0 PL for Windows (IBM Corp., Armonk, USA). Pearson's $\chi^{2}$ test compared the sample distribution of variables to their theoretical distribution. Cramér's V measured the correlation between 2 assessed nominal variables. Statistical significances were expressed quantitatively and set at $\mathrm{p} \leq 0.05$.

\section{Results}

The prevalence of functional disorders was different in the treatment group (with speech sound disorders) and the control group (without speech sound disorders). Among the 10 functional disorders (6 parafunctional habits and 4 dysfunctions) assessed, the results referring to nail biting, prolonged bottle feeding, teeth clenching, and lazy chewing were found statistically insignificant. The remaining disorders occurred more often in the treatment group, and those results met the criteria for statistical significance.

The correlation between speech sound disorders and any parafunctional habits was weak, but statistically significant. It was slightly higher for occlusal than non-occlusal parafunctional habits.

The coexistence of occlusal parafunctional habits and speech sound disorders was also statistically significant. Occlusal parafunctional habits were exhibited 2 times more often in the treatment group than in the control group and their correlation with speech sound disorders was moderately strong.

A strong correlation exists between the prevalence of speech sound disorders and non-occlusal parafunctions: prolonged pacifier use, sucking habits and lip or mucosa biting. However, such a correlation was not observed for speech sound disorders and nail biting - their $\chi^{2}$ test results indicated a considerable risk of being random. 
The correlation between speech sound disorders and any type of dysfunction was much stronger than with any parafunctional habit (Cramér's V at 0.405 vs 0.188 ).

Oral breathing and persistent tongue thrust were common dysfunctions in the treatment group; persistent tongue thrust (Cramér's V at 0.387) and mouth breathing (Cramér's V at 0.378) had the strongest correlations with speech sound disorders.

Table 1 presents the prevalence of functional disorders and their correlation with speech sound disorders measured with Cramér's V.

The correlations between functional disorders and speech sound disorders, measured with Cramér's V, for persistent tongue thrust, oral breathing and sucking habits were strong. Lip or mucosa biting, prolonged pacifier use and tooth grinding ranked next according to the strength of their correlation with speech sound disorders.

The present study revealed 72 correlations between anatomical abnormalities and errors in the articulation of respective sound groups, of which 52 were statistically significant ( $\mathrm{p} \leq 0.05)$ (Table 2).

There were strong correlations (Cramér's V 0.3-0.5) between the prevalence of:

1. Oral breathing and errors in $/ \mathrm{p} /, / \mathrm{b} /$ and $/ \mathrm{m} /$ sounds;

2. Any dysfunction and errors in $/ \mathrm{p} /, / \mathrm{b} /$ and $/ \mathrm{m} /$ sounds;

3. Persistent tongue thrust and errors in $/ \mathrm{s} /, / \mathrm{z} /, / \mathrm{ts} /$, and $/ \widehat{\mathrm{dz}} /$ sounds;

4. Oral breathing and errors in $/ \mathrm{s} /, / \mathrm{z} /, \widehat{\mathrm{ts}} /$, and $/ \widehat{\mathrm{dz}} /$ sounds;

5. Any dysfunction and errors in $/ \mathrm{s} /, / \mathrm{z} /, \widehat{\mathrm{ts}} /$, and $/ \widehat{\mathrm{dz}} /$ sounds;

6. Sucking habits and errors in $/ \mathrm{s} /, / \mathrm{z} /, / \mathrm{ts} /$, and $/ \widehat{\mathrm{dz}} /$ sounds;

7. Persistent tongue thrust and errors in $/ \mathrm{s} /, / \mathrm{zl} /, / \mathrm{ts} /$, and $/ \widehat{\mathrm{dz}} /$ sounds;

8. Sucking habits and errors in $/ \mathrm{s} /, / \mathrm{z} /, \widehat{\mathrm{ts}_{\mathrm{S}}} /$, and $/ \widehat{\mathrm{dz}} /$ sounds;
9. Persistent tongue thrust and errors in $/ \mathrm{s} /, / \mathrm{z} l, \widehat{\mathrm{ts}} /$, and $/ \widehat{\mathrm{dz}} /$ sounds;

10. Oral breathing and errors in $/ \mathrm{s} /, / \mathrm{z} /, /$ ts $/$, and $/ \widehat{\mathrm{dz}} /$ sounds;

11. Any dysfunction and errors in $/ \mathrm{s} /, / \mathrm{z} /, / \mathrm{ts}_{\mathrm{s}} /$, and $/ \widehat{\mathrm{dz}} /$ sounds; and

12. Sucking habits and errors in /s $/, / \mathrm{z} /, / \mathrm{ts} /$, and $/ \widehat{\mathrm{dz}} /$ sounds.

\section{Discussion}

There have been no comprehensive studies on parafunctional habits and dysfunctions of the masticatory system, and their correlation with speech sound disorders. Existing studies were focused on specific disorders of the masticatory system and their coexistence with speech sound disorders. They were also not aimed at assessing the strength of this relation in a quantitative manner. However, their results may be compared to partial findings of the present study.

In this study, occlusal parafunctional habits prevailed 2 times more often in the treatment group than in the control group and their correlation with speech sound disorders was moderately strong. The chi-squared test results confirmed that the correlation between occlusal parafunctional habits and errors in $/ \mathrm{t} /, / \mathrm{d} /$ and $/ \mathrm{n} /$ sounds were statistically significant. Pizzolato et al. concluded that occlusal alterations concurred with errors of alveolar /s/, /z/, /t/, /d/, and /n/ and postalveolar $/ 1 / .^{3}$

Speech and sound disorders were observed more often in cases of prolonged pacifier use. Precisely $47 \%$ of children with speech sound disorders and $30 \%$ of those without speech sound disorders were found to have used the pacifier over longer periods of time. In a study on improp-

Table 1. Prevalence of functional disorders of the masticatory system and their correlation with speech sound disorders

\begin{tabular}{|c|c|c|c|}
\hline \multirow[b]{2}{*}{$\begin{array}{l}\text { Type of functional disorder } \\
\text { (\% in treatment and control group) }\end{array}$} & \multicolumn{2}{|c|}{ Prevalence - $\%$ of children in: } & \multirow{2}{*}{$\begin{array}{l}\text { Correlation between the } \\
\text { prevalence of parafunctional habits, } \\
\text { dysfunctions and speech sound } \\
\text { disorders (Cramér's V) }\end{array}$} \\
\hline & $\begin{array}{c}\text { group with articulation } \\
\text { disorders (treatment group) } \\
\qquad n=161\end{array}$ & $\begin{array}{l}\text { group without speech sound } \\
\text { disorders (control group) } \\
n=139\end{array}$ & \\
\hline Parafunctional habits in general & 87.6 & 72.7 & 0.188 \\
\hline Occlusal parafunctional habits, including & 46.0 & 23.7 & 0.231 \\
\hline teeth clenching* & 15.5 & 7.2 & 0.129 \\
\hline teeth grinding & 30.4 & 16.5 & 0.162 \\
\hline Non-occlusal parafunctional habits, including* & 78.9 & 66.2 & 0.143 \\
\hline prolonged pacifier use & 47.2 & 29.5 & 0.181 \\
\hline sucking habits & 34.2 & 7.2 & 0.326 \\
\hline nail biting* & 36.6 & 35.3 & 0.014 \\
\hline lip or mucosa biting & 16.1 & 2.2 & 0.236 \\
\hline Dysfunctions in general & 59.0 & 15.1 & 0.405 \\
\hline oral breathing & 45.3 & 10.8 & 0.378 \\
\hline persistent tongue thrust & 29.2 & 0.7 & 0.387 \\
\hline prolonged bottle feeding* & 18.6 & 13.7 & 0.105 \\
\hline lazy chewing* & 6.2 & 12.2 & 0.120 \\
\hline
\end{tabular}

* result statistically insignificant ( $p \leq 0.05)$. 
Table 2. Prevalence of incorrect pronunciation of groups of speech sounds and its correlation with given functional disorders of the masticatory system

\begin{tabular}{|c|c|c|c|c|c|c|c|c|}
\hline Groups of speech sounds & \multicolumn{2}{|c|}{ Alveolar } & \multicolumn{2}{|c|}{ Postalveolar } & \multicolumn{2}{|c|}{ Pre-palatal } & Bilabial & Labiodental \\
\hline $\begin{array}{l}\text { Type of functional disorder } \\
\text { (number of patients in both treatment } \\
\text { and control groups, Cramér's V) }\end{array}$ & $\begin{array}{l}/ \mathrm{s} /, / \mathrm{z} / \\
/ \mathrm{ts} /, / \mathrm{dz} /\end{array}$ & $/ \mathrm{t} /, / \mathrm{d} /, / \mathrm{n} /$ & $\begin{array}{l}/ \mathrm{s} /, / \mathrm{z} / \\
\mid / \mathrm{t} /, / \mathrm{dz} /\end{array}$ & $/ \mathrm{r} /, \mathrm{N} /$ & $/ \mathrm{n} /, / \mathrm{j} /$ & $\begin{array}{l}\mid \mathrm{b} /, / \mathrm{z} / \\
\mid \mathrm{t} 6 /, / \mathrm{d} \mathrm{t} /\end{array}$ & $/ \mathrm{p} /, / \mathrm{b} /, / \mathrm{m} /$ & $/ \mathrm{V} /, / \mathrm{f} /$ \\
\hline $\begin{array}{l}\text { Any parafunctional habit } \\
\text { (parafunctional habits in general) } \\
n=242\end{array}$ & $\begin{array}{l}38.8 \% \\
(0.165)\end{array}$ & $\begin{array}{l}25.2 \% \\
(0.176)\end{array}$ & $\begin{array}{l}31.4 \% \\
(0.187)\end{array}$ & * & * & $\begin{array}{l}38.8 \% \\
(0.179)\end{array}$ & * & * \\
\hline $\begin{array}{l}\text { Teeth grinding } \\
n=72\end{array}$ & $\begin{array}{l}48.6 \% \\
(0.160)\end{array}$ & $\begin{array}{l}36.1 \% \\
(0.197)\end{array}$ & * & $\begin{array}{l}38.9 \% \\
(0.165) \\
\text { (only /r/) }\end{array}$ & * & $\begin{array}{l}51.4 \% \\
(0.197)\end{array}$ & * & * \\
\hline $\begin{array}{l}\text { Prolonged pacifier use } \\
n=117\end{array}$ & $\begin{array}{l}51.3 \% \\
(0.273)\end{array}$ & $\begin{array}{l}33.3 \% \\
(0.226)\end{array}$ & $\begin{array}{l}37.6 \% \\
(0.184)\end{array}$ & * & * & $\begin{array}{l}48.7 \% \\
(0.236)\end{array}$ & * & $\begin{array}{l}2.7 \% \\
(0.220)\end{array}$ \\
\hline $\begin{array}{l}\text { Sucking habits } \\
n=6\end{array}$ & $\begin{array}{l}73.8 \% \\
(0.428)\end{array}$ & $\begin{array}{l}55.4 \% \\
(0.430)\end{array}$ & $\begin{array}{l}56.9 \% \\
(0.349)\end{array}$ & $\begin{array}{c}46.2 \% \\
(0.242) \\
\text { (only } / \mathrm{r} / \text { ) }\end{array}$ & $\begin{array}{c}20 \% \\
(0.167) \\
\text { (only } / \mathrm{n} /)\end{array}$ & $\begin{array}{l}67.5 \% \\
(0.382)\end{array}$ & $\begin{array}{l}18.5 \% \\
(0.276)\end{array}$ & $\begin{array}{l}10.8 \% \\
(0.240)\end{array}$ \\
\hline $\begin{array}{l}\text { Lip or mucosa biting } \\
\mathrm{n}=29\end{array}$ & $\begin{array}{l}75.9 \% \\
(0.280)\end{array}$ & $\begin{array}{l}58.6 \% \\
(0.293)\end{array}$ & $\begin{array}{l}62.1 \% \\
(0.255)\end{array}$ & * & $\begin{array}{c}27.6 \% \\
(0.185) \\
\text { (only } / \mathrm{n} /)\end{array}$ & $\begin{array}{l}69.0 \% \\
(0.236)\end{array}$ & * & * \\
\hline $\begin{array}{l}\text { Any type of dysfunction } \\
\text { (dysfunctions in general) } \\
\mathrm{n}=116\end{array}$ & $\begin{array}{l}60.3 \% \\
(0.442)\end{array}$ & $\begin{array}{l}42.2 \% \\
(0.397)\end{array}$ & $\begin{array}{c}44 \% \\
(0.296)\end{array}$ & $\begin{array}{l}36.2 \% \\
(0.185) \\
\text { (only /r/) }\end{array}$ & $\begin{array}{l}17.2 \% \\
(0.180)\end{array}$ & $\begin{array}{l}58.6 \% \\
(0.400)\end{array}$ & $\begin{array}{l}15.5 \% \\
(0.318)\end{array}$ & $\begin{array}{c}6.9 \% \\
(0.181)\end{array}$ \\
\hline $\begin{array}{l}\text { Persistent tongue thrust } \\
n=48\end{array}$ & $\begin{array}{l}83.3 \% \\
(0.442)\end{array}$ & $\begin{array}{l}54.2 \% \\
(0.344)\end{array}$ & $\begin{array}{l}58.3 \% \\
(0.304)\end{array}$ & $\begin{array}{c}25 \% \\
(0.239)\end{array}$ & $\begin{array}{l}22.9 \% \\
(0.180) \\
\text { (only } / \mathrm{n} /)\end{array}$ & $\begin{array}{l}77.1 \% \\
(0.389)\end{array}$ & $\begin{array}{l}18.8 \% \\
(0.234)\end{array}$ & * \\
\hline $\begin{array}{l}\text { Oral breathing } \\
n=88\end{array}$ & $\begin{array}{l}61.4 \% \\
(0.356)\end{array}$ & $\begin{array}{l}45.5 \% \\
(0.372)\end{array}$ & $\begin{array}{l}46.6 \% \\
(0.278)\end{array}$ & * & $\begin{array}{l}18.2 \% \\
(0.176)\end{array}$ & $\begin{array}{l}58.0 \% \\
(0.315)\end{array}$ & $\begin{array}{l}20.5 \% \\
(0.392)\end{array}$ & $\begin{array}{c}8 \% \\
(0.187)\end{array}$ \\
\hline
\end{tabular}

* result statistically insignificant $(p \leq 0.05)$.

er function of the tongue, also in the context of speech, Straub established a statistically significant correlation between pacifier use and speech sound disorders. ${ }^{4}$ However, a study by Shotts et al. did not suggest that there were significant differences in articulation related to prolonged pacifier use. ${ }^{5}$

Sucking habits (finger, thumb or lip) and speech sound disorders were strongly correlated. Van Norman and Tarvade et al. observed that children who persist in nonnutritive sucking of the thumb or finger beyond early childhood are more likely to develop speech difficulties. ${ }^{6,7}$ It has been also confirmed that sucking habits are correlated with malocclusions, and malocclusions co-occur with speech sound disorders. ${ }^{8-11}$ There were no studies on the correlation between sucking habits and specific speech sound disorders.

Nail biting was a statistically insignificant parafunctional habit. Only 1 more child bit its nails in the treatment group than in the control group. However, Straub came to completely different conclusions - he established that nail biting led to an improper function of the tongue, including speech sound disorders. ${ }^{4}$

The correlation between speech sound disorders and persistent tongue thrust was strong. Zadurska et al. established the same $-61 \%$ of children with persistent tongue thrust had speech sound disorders. In the present study, this percentage was much higher $-98 \%$. Therefore, per- sistent tongue thrust seems to lead to speech sound disorders. Straub, Tarvade et al., Rehak et al., Hopkin and Mackiewicz confirmed this theory. ${ }^{7,12-14}$

Subtelny and Subtelny often observed, when assessing the impact of tongue thrust on speech sound disorders, adapted patients with malocclusions and normal speech; however, all patients with an improper function of the tongue had speech sound disorders. ${ }^{15}$ In later studies, Subtelny first established that $72 \%$ of patients with normal swallowing and $40 \%$ of patients with tongue thrust did not have speech sound disorders, and then subsequently that $63 \%$ of patients with normal swallowing and $1 \%$ of patients with tongue thrust did not have speech sound disorders. ${ }^{16}$

Fieux (citing Szlachetko) published the results of cinematoradiographic studies on swallowing and speech. ${ }^{17}$ Children with persistent tongue thrust touched their lower lip with the tip of their tongue when articulating most speech sounds, although it was not always audible, i.e., either the produced sound or the position of speech organs was improper. Rix and Cleall, who took cineradiographic images of the swallowing process, focused not only on improper tongue posture, but also on other structures, and came to similar conclusions. ${ }^{18,19}$ Cleall established that persistent tongue thrust impacted the anatomy and motility of the stomatognathic system. ${ }^{19}$ Horn et al., who studied improper swallowing with electromagnetic articulography, came to similar conclusions. ${ }^{20}$ 
In the present study, persistent tongue thrust concurred with errors in bilabial $(/ \mathrm{p} /, / \mathrm{b} /, / \mathrm{m} /)$, alveolar $(/ \mathrm{t} /$, $/ \mathrm{d} /, / \mathrm{n} /, / \mathrm{s} /, / \mathrm{z} /, / \mathrm{ts} /, / \widehat{\mathrm{dz}} /)$, postalveolar $(/ \mathrm{s} /, / \mathrm{zl} /, \mid \widehat{\mathrm{ts}} /, / \widehat{\mathrm{dz}} /$, $/ \mathrm{r} /, / \mathrm{l} /)$, and pre-palatal $\left(/ \mathrm{c} /, / \mathrm{z} /, / \mathrm{t}_{6} /, / \overline{\mathrm{d}} / \mathrm{l} / \mathrm{n} /\right)$ sounds. Straub, Subtelny as well as Clausnitzer and Clausnitzer described concurrent improper swallowing and errors in the /s/ sound. ${ }^{4,16,21}$

Oral breathing occurred 5 times more frequently in children with speech sound disorders than in children without speech sound disorders. This correlation was strong and statistically significant. Hitos et al. concluded that mouth breathing can affect speech development. ${ }^{22}$ Zadurska et al. also established a correlation between mouth breathing and speech sound disorders. ${ }^{11}$ However, the percentage of mouth breathing children with speech sound disorders was lower (59\%) in the quoted studies than in the present study (82\%).

The correlation between speech sound disorders and prolonged bottle feeding was statistically insignificant. Significance was much higher than 0.05 (0.246). This outcome is contrary to Straub's results, who established that artificial feeding (bottle with the wrong nipple) or prolonged bottle feeding in early childhood led to improper swallowing, improper tongue posture and speech sound disorders. ${ }^{4}$ Subtelny obtained results similar to Straub's. ${ }^{16}$ Also, Barbosa et al. suggested that extended use of bottle feeding and other sucking behaviors may have detrimental effects on speech. ${ }^{23}$

\section{Conclusions}

Functional disorders of the masticatory system, apart from teeth clenching, nail biting, prolonged bottle feeding, and lazy chewing, concur more often with speech sound disorders than with proper articulation, and are a material cause of speech sound disorders.

There is a strong correlation between: any type of dysfunction and errors in $/ \mathrm{p} /, / \mathrm{b} /, / \mathrm{m} /, / \mathrm{s} /, / \mathrm{z} /, / \mathrm{ts} /$, $/ \widehat{\mathrm{dz}} /, / \mathrm{c} /, / \mathrm{z} /, \mid \widehat{\mathrm{t}} \mathrm{l} /$, and $/ \widehat{\mathrm{d} z} /$ sounds; oral breathing and errors in $/ \mathrm{p} /, / \mathrm{b} /, / \mathrm{m} /, / \mathrm{s} /, / \mathrm{z} /, / \mathrm{ts} /, / \widehat{\mathrm{dz}} /, / \mathrm{c} /, \mid \mathrm{z} /, / \widetilde{\mathrm{t}} /$, and $/ \widehat{\mathrm{d} z /} /$ sounds; persistent tongue thrust and errors in $/ \mathrm{s} /, \mathrm{z} /$,

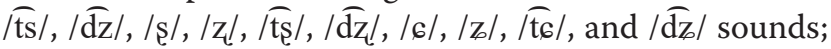
and sucking habits and errors in $/ \mathrm{s} /, / \mathrm{z} /, \widehat{\mathrm{ts}} /, / \widehat{\mathrm{dz}} /, / \mathrm{s} /, / \mathrm{zl} /$,

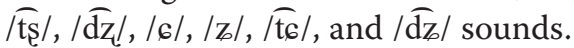

Knowledge on functional correlations between the masticatory system and speech sound disorders makes it possible to introduce effective prevention and treatment at the right moment. Dentists and speech therapists could work together, understanding the correlation between the structure and the function of the stomatognathic system, and focusing on the causes of speech sound disorders and concurrent dental disorders. It could shorten treatment duration and minimize the risk of relapse after the treatment's conclusion.

\section{References}

1. Wiesner G. Speech intelligibility. In: Ball MJ, Perkins MR. The Handbook of Clinical Linguistics. Oxford, UK: Blackwell Publishers; 2008:568-582.

2. Olczak-Kowalczyk D, Grudziąż-Sękowska J. Interdependence between malocclusion and articulatory disorders - preliminary communication [in Polish]. Nowa Stomatol. 2010;15:62-67.

3. Pizzolato RA, Fernandes FSF, Gaviao MBD. Speech evaluation in children with temporomandibular disorders. J Appl Oral Sci. 2011;19:493-499.

4. Straub JW. Malfunction of the tounge. Am JOrthod. 1960;46:404-424.

5. Shotts LL, McDaniel DM, Neeley RA. The impact of prolonged pacifier use on speech articulation: A preliminary investigation. Contemp Issues Commun Sci Disord. 2008;35:72-75.

6. Van Norman RA. Why we can't afford to ignore prolonged digit sucking. Contemp Pediatr. 2001;2:61-80.

7. Tarvade SM, Ramkrishna S. Tongue thrusting habit: A review. Int J Contemp Dent Med Rev. 2015:1-5. doi: 10.15713/ins.ijcdmr.26

8. Babiak M, Babiak J, Marcinkowski J. Frequency of malocclusion in 4-, 5- and 6-year-old children with oral habits [in Polish]. Probl Hig Epidemiol. 2012;93:319-326.

9. Zadurska M, Piekarczyk B, Fidecki M, et al. Evaluation of malocclusion in preschool children undergoing speech therapy [in Polish]. In: Diagnosis and Therapy in Speech Therapy. Porayski-Pomsta J, ed. Warszawa, Poland: Dom Wydawniczy Elipsa; 2008:110-116.

10. Orzelska-Blomberg M, Kuropatnicka M, Szkarłat B, WojtaszekSłomińska A, Grzybiak M. Frequency of malocclusion and articulation disorders in preschool children [in Polish]. Forum Ortodont. 2015;11:8-15.

11. Zadurska M, Siemińska-Piekarczyk B, Wierusz W, Mysiorska M, Kosińska K. Evaluation of the correlation between the occurrence of malocclusion and speech disorder and dysfunction of stomatognathic system among children from nursery schools in Warsaw [in Polish]. Stomatol Wspolcz. 2007; Suppl 2:17-22.

12. Rehak G, Kovacs E, Frigyesi A. The relationship between malocclusion, abnormal swallowing and lisping [in Polish]. Czas Stomatol. 1974;28:559-562.

13. Hopkin GB. Orthodontic aspects of the diagnosis and management of speech defects in children. Proc R Soc Med. 1972;65:409-414.

14. Mackiewicz B. Interdependence between malocclusion and articulatory disorders on the causal basis [in Polish]. Magazyn Stomatol. 1992;2:28-30.

15. Subtelny JD, Subtelny JD. Malocclusion, speech and deglutition. Am J Orthod Dentofacial Orthop. 1962;48:685-697.

16 Subtelny JD. Examination of current philosophies associated withswallowing behavior. Am J Orthod. 1965;51:161-182.

17. Szlachetko K. Pathological deglutition in etiopathogenesis of malocclusion [in Polish]. Czas Stomatol. 1965;18:1251-1255.

18. Rix RE. Deglutition and the teeth. Dent Rec (London). 1953;4:427-442.

19. Cleall JF. Deglutition: A study of form and function. Am J Orthod. 1965;51:566-594.

20. Horn H, Kuhnast K, Axmann-Krcmar D, Goz G. Influence of orofacial dysfunctions on spatial and temporal dimensions of swallowing movements. J Orofac Orthop. 2004;65:376-388.

21. Clausnitzer R, Clausnitzer V. Relationships between dysgnathia, formation mode of the $\mathrm{S}$ and faulty swallowing [in German]. Stomatol DDR. 1989;39:569-572.

22. Hitos SF, Arakaki R, Sole D, Weckx LLM. Oral breathing and speech disorders in children. J Pediatr. 2013;89:361-365.

23. Barbosa C, Vasquez S, Parada MA, et al. The relationship of bottle feeding and other sucking behaviors with speech disorder in Patagonian pre-schoolers. BMC Pediatr. 2009;9:66. 
